\title{
BRONCHOPULMONARY CARCINOID TUMORS ASSOCIATED WITH CUSHING'S SYNDROME: A MORE AGGRESSIVE VARIANT OF TYPICAL CARCINOID
}

Joseph B. Shrager, MD

Cameron D. Wright, MD

John C. Wain, MD

David F. Torchiana, MD

Hermes C. Grillo, MD

Douglas J. Mathisen, MD
Objectives: Our objectives were to delineate the clinicopathologic characteristics of adrenocorticotropin-secreting bronchopulmonary carcinoid tumors causing Cushing's syndrome and to derive from these findings a rational approach to diagnosis and surgical management of this unusual condition. Methods: We conducted a retrospective, chart-review analysis of seven consecutive patients treated at the Massachusetts General Hospital over a 16-year period. Results: The patients uniformly had symptoms of marked hypercortisolism, and the underlying lung lesions remained clinically occult for a mean of 24 months. Standard endocrine testing was misleading in $83 \%$ of patients, reinforcing the need for an alternative diagnostic strategy based on petrosal sinus catheterization and computed tomography of the chest. Although $72 \%$ of the tumors were typical carcinoids by standard criteria, $57 \%$ demonstrated microscopic evidence of local invasiveness, and $43 \%$ were associated with mediastinal lymph node metastases. Eighty-six percent of patients have been cured by pulmonary resection a mean of $\mathbf{5 9}$ months after the operation, but $50 \%$ of these required a second operation for resection of involved lymph nodes after an initial relapse. Conclusions: These data suggest that adrenocorticotropinsecreting bronchopulmonary carcinoid tumors represent a distinct, more aggressive subtype of the usual, typical carcinoid. The high rate of lymphatic and local spread demands a surgical approach consisting of anatomic resection and routine mediastinal lymph node dissection. (J Thorac Cardiovasc Surg 1997;114:367-75)
B ronchopulmonary carcinoids are low- to moderate-grade malignant neoplasms. As a result of their origin from neuroendocrine cells, these tumors frequently secrete biologically active peptides. The most common of these is serotonin, implicated as the cause of the carcinoid syndrome, which occurs in up to $12 \%$ of patients with bronchial carcinoids. ${ }^{1}$ Less commonly, bronchial carcinoids elaborate hormones resulting in Cushing's syndrome, usually adrenocorticotropin (ACTH). ${ }^{2,3}$ Although bronchial

From the Department of Surgery, Harvard Medical School, and the Thoracic Surgical Unit of the Surgical Services, Massachusetts General Hospital, Boston, Mass.

Received for publication Jan. 27, 1997; revisions requested Feb. 26, 1997; revisions received April 21, 1997; accepted for publication April 22, 1997.

Address for reprints: Douglas J. Mathisen, MD, Thoracic Surgical Unit, 11 Warren, Massachusetts General Hospital, 55 Fruit St., Boston, MA 02114

Copyright ( 1997 by Mosby-Year Book, Inc.

$0022-5223 / 97 \$ 5.00+0 \quad \mathbf{1 2 / 1 / 8 2 7 6 3}$ carcinoids account for only $1 \%$ of cases of Cushing's syndrome, ${ }^{4}$ most patients in whom this syndrome develops as a result of ectopic ACTH production have a source within the thorax. Among these intrathoracic sources, only bronchial carcinoids are likely to be cured. ${ }^{5}$ This high therapeutic success rate, along with the remarkable clinical syndrome that these patients exhibit, lends unusual clinical interest to the association of bronchial carcinoids and Cushing's syndrome.

Most documented cases of hypercortisolism associated with bronchial carcinoids have been reported individually. We present a series of seven consecutive patients with this disease process, which confirms and extends the findings of previous small series. Our findings highlight the fact that although they are usually identified as typical carcinoids, bronchopulmonary carcinoids associated with Cushing's syndrome have a much more aggressive clinical behavior than other typical carcinoids and therefore require more aggressive surgical treatment than that which is accepted for other typical carcinoids. 
Table I. Clinical and pathologic characteristics of seven patients with Cushing's syndrome caused by bronchopulmonary carcinoid tumors

\begin{tabular}{|c|c|c|c|c|c|}
\hline $\begin{array}{l}\text { Patient } \\
\text { (year) }\end{array}$ & Age, sex & Imaging studies & Endocrine studies & $\begin{array}{c}\text { Time to } \\
D x\end{array}$ & Hypophysectomy \\
\hline $\begin{array}{c}1 \\
(1981)\end{array}$ & $22, \mathrm{M}$ & $\begin{array}{l}\text { Sella tomos }(-) \text {; CT abd }(-) \\
\text { CXR }(-) ; \text { CT chest }(+) ; \\
\text { pulm angio }(-)\end{array}$ & $\begin{array}{l}\text { Urine cort 174; ACTH } 102 ; \\
\text { low-dose dex-no sup; } \\
\text { high-dose dex-sup }\end{array}$ & $12 \mathrm{mo}$ & Yes, 2 \\
\hline $\begin{array}{c}2 \\
(1986)\end{array}$ & $20, \mathrm{~F}$ & $\begin{array}{l}\text { CT head }(-) ; \text { CT abd }(-) \text {; } \\
\text { CXR }(-) ; \text { CT chest }(+)\end{array}$ & $\begin{array}{l}\text { Urine cort 549; ACTH 99; } \\
\text { low-dose dex-no sup; } \\
\text { high dose dex-sup; petr } \\
\text { cath-central }\end{array}$ & $12 \mathrm{mo}$ & Yes \\
\hline $\begin{array}{c}3 \\
(1988)\end{array}$ & $23, \mathrm{M}$ & $\begin{array}{l}\text { MRI head equiv; CT abd } \\
(-) ; \operatorname{CXR}(-) ; \mathrm{CT} / \mathrm{MRI} \\
\text { chest }(+)\end{array}$ & $\begin{array}{l}\text { Urine cort 1000; ACTH } \\
\text { 112; low-dose dex--no } \\
\text { sup; high dose dex-sup; } \\
\text { petr cath-ectopic }\end{array}$ & $31 \mathrm{mo}$ & Yes \\
\hline $\begin{array}{c}4 \\
(1992)\end{array}$ & $45, \mathrm{M}$ & $\begin{array}{l}\text { CT/MRI head (-); CT abd } \\
(-) ; \text { CXR }(-) ; \text { CT chest } \\
(+) ; \text { octr scan }(+)^{*}\end{array}$ & $\begin{array}{l}\text { Urine cort 2189; ACTH } \\
\text { 191; low-dose dex-no } \\
\text { sup; high-dose dex- } \\
\text { sup }\end{array}$ & $8 \mathrm{mo}$ & No \\
\hline $\begin{array}{c}5 \\
(1994)\end{array}$ & $74, \mathrm{~F}$ & $\begin{array}{l}\text { MRI head }(-) ; \text { CXR }(-) \text {; } \\
\text { CT chest }(+)\end{array}$ & $\begin{array}{l}\text { Urine cort 500; ACTH } 77 \text {; } \\
\text { low-dose dex-no sup; } \\
\text { high dose dex-sup; petr } \\
\text { cath-ectopic }\end{array}$ & $6 \mathrm{mo}$ & No \\
\hline $\begin{array}{c}6 \\
(1995)\end{array}$ & $51, \mathrm{M}$ & $\begin{array}{l}\text { MRI head }(-) \text {; CT abd }(-) \text {; } \\
\text { CXR }(+) \text {; CT chest }(+)\end{array}$ & $\begin{array}{l}\text { Urine cort 929; ACТН 97; } \\
\text { low-dose dex-no sup; } \\
\text { high-dose dex-no sup; } \\
\text { petr cath-ectopic }\end{array}$ & $84 \mathrm{mo}$ & No \\
\hline $\begin{array}{c}7 \\
(1996)\end{array}$ & $37, \mathrm{M}$ & $\begin{array}{l}\text { MRI head }(-) \text {; CT abd }(-) \text {; } \\
\text { CXR }(-) ; \text { octr scan }(+) \dagger \\
\text { CT chest }(+) \neq\end{array}$ & $\begin{array}{l}\text { Urine free cort } 563 \text {; ACTH } \\
\text { 100; low-dose dex--no } \\
\text { sup; high-dose dex } \$ \text {; petr } \\
\text { cath-ectopic }\end{array}$ & $18 \operatorname{mos}$ & No \\
\hline
\end{tabular}

$D X$, Diagnosis; abd, abdomen; pulm angio, pulmonary angiography; urine cort, urinary free cortisol level; low/high-dose dex, low/high dose dexamethasone suppression test; sup, positive suppression of cortisol and ACTH levels; petr cath, inferior petrosal sinus ACTH sampling; equiv, equivocal result; (-), negative or normal study or lymph node; $(+)$, positive study or lymph node involved with neoplastic process; $L N$, lymph node; octr, octreotide.

*To diagnose recurrent disease in subcarinal node.

$\uparrow$ For both initial disease and residual disease.

$\Varangle$ High-resolution CT of chest was positive after standard cut CT of chest was negative for tumor.

$\$$ Result not available.

\section{Patients and methods}

Between 1980 and 1996, seven patients were treated at the Massachusetts General Hospital for Cushing's syndrome resulting from ectopic ACTH production by a bronchopulmonary carcinoid tumor (Table I). The medical records and pathologic specimens of these patients were reviewed with attention to symptoms, diagnostic studies and time to diagnosis, surgical treatment, pathology, and outcome. The mean age of the patients was 34 years. The group comprised five men and two women.

Computed tomography (CT) of the chest was performed without contrast media by means of $10 \mathrm{~mm}$ cuts, except at the hila, where $5 \mathrm{~mm}$ cuts were used. Areas of interest were further delineated with $1.5 \mathrm{~mm}$ cuts. Highresolution scans used $5 \mathrm{~mm}$ cuts throughout the thorax. The low-dose dexamethasone suppression test involved measurement of cortisol levels after $0.5 \mathrm{mg}$ orally every 6 hours for 48 hours; the high-dose test used $2 \mathrm{mg}$ orally every 6 hours for 48 hours. Octreotide scans were per- formed with multiple planar and single-photon emission computed tomography images of the head, neck, chest, and abdomen obtained 4 and 24 hours after intravenous administration of $200 \mathrm{mBg}$ of indium 111-labeled pentotreotide. Bilateral inferior petrosal sinus sampling was performed by placement of a $5 \mathrm{~F}$ catheter into each internal jugular vein through a $5.5 \mathrm{~F}$ introducer in a common femoral vein. After the administration of 5000 units of heparin, $2.9 \mathrm{~F}$ catheters were threaded into each inferior petrosal sinus and their positions confirmed by injection of contrast material. Venous samples for ACTH were drawn simultaneously from each sinus and from the right common femoral vein at baseline and at 3, 5, 10, and 15 minutes after intravenous injection of corticotropinreleasing hormone. Cushing's disease is suggested by a gradient from the central to peripheral ACTH levels, and the lack of a gradient suggests ectopic ACTH production.

Operations were performed by means of a thoracotomy with perioperative intravenous steroid coverage, preoper- 


\begin{tabular}{|c|c|c|c|}
\hline $\begin{array}{l}\text { Initial thoracic } \\
\text { procedure }\end{array}$ & Second thoracic procedure & Pathology & Outcome \\
\hline $\begin{array}{c}\text { Bronchoscopy }(-) \\
\text { wedge resection }\end{array}$ & $\begin{array}{l}\text { Right lower lobectomy } 12 \text { days } \\
\text { postop for failure to nor- } \\
\text { malize hormone levels and } \\
\text { aggressive pathology }\end{array}$ & $\begin{array}{l}\text { Atypical carcinoid; lymphatic } \\
\text { and aerogenous metastases; } \\
3 \text { hilar; } 1 \text { lobar LN }(+) \\
\text { second operation }\end{array}$ & Disease free \\
\hline $\begin{array}{c}\text { Bronchoscopy }(-) \\
\text { wedge resection }\end{array}$ & None & $\begin{array}{l}\text { Typical carcinoid; extensive } \\
\text { lymphatic invasion; no } \\
\text { modes in specimen }\end{array}$ & $\begin{array}{l}\text { Recurrent Cushing's } 9 \\
\text { mo postop, no source } \\
\text { ID'd, bilateral adrenal- } \\
\text { ectomy }\end{array}$ \\
\hline $\begin{array}{l}\text { Bronchoscopy }(-) \text {; } \\
\text { left upper lobec- } \\
\text { tomy; mediastinal } \\
\text { LN dissection }\end{array}$ & None & $\begin{array}{l}\text { Typical carcinoid; } 1 \text { peribron- } \\
\text { chial and } 3 \text { mediastinal } \\
\mathrm{LN}(+)\end{array}$ & Disease free \\
\hline $\begin{array}{l}\text { Bronchoscopy }(-) \\
\text { right lower lo- } \\
\text { bectomy }\end{array}$ & $\begin{array}{l}\text { Mediastinal LN dissection } 29 \text { mo } \\
\text { postop after recurrent hormone } \\
\text { elevations and }(+) \text { octr scan }\end{array}$ & $\begin{array}{l}\text { Typical carcinoid; lymphangitic } \\
\text { spread; } 3 \text { N1 LN's }(+) \text { and } \\
\text { subcarinal LN }(+) \text { at second } \\
\text { operation }\end{array}$ & Disease free \\
\hline $\begin{array}{l}\text { Bronchoscopy }(-) \\
\text { right middle lo- } \\
\text { bectomy }\end{array}$ & None & Typical carcinoid; all LN's (-) & Disease free \\
\hline $\begin{array}{l}\text { Bronchoscopy }(-) \\
\text { precision cautery } \\
\text { excision }\end{array}$ & None & Typical carcinoid & Disease free \\
\hline $\begin{array}{l}\text { Bronchoscopy }(-) \text {; } \\
\text { left upper lobe } \\
\text { anterior segmen- } \\
\text { tectomy }\end{array}$ & $\begin{array}{l}\text { Completion left upper lobec- } \\
\text { tomy, mediastinal LN dissec- } \\
\text { tion } 4 \text { weeks postop after } \\
\text { failure to normalize and }(+) \\
\text { octr scan }\end{array}$ & $\begin{array}{l}\text { Frozen section at first opera- } \\
\text { tion-typical carcinoid; per- } \\
\text { manents-atypical; } 1 \mathrm{~N} 1 \text { and } \\
1 \mathrm{~N} 2 \mathrm{LN}(+) \text { at second op- } \\
\text { eration }\end{array}$ & Disease free \\
\hline
\end{tabular}

ative antibiotics, and single lung ventilation. Patients were slowly weaned from steroids after the operation after documentation that a fall to normal serum ACTH levels had been achieved.

\section{Results}

Symptoms. The patients with carcinoid-induced Cushing's syndrome demonstrated the typical clinical spectrum of severe hypercortisolism. Common signs and symptoms included muscle weakness or fatigue (all 7 patients), weight gain (6/7), striae (5/7), hypertension $(5 / 7)$, acne $(3 / 7)$, and "moon face" $(3 / 7)$. Each of the patients had at least three of these symptoms. Only one of the patients had superimposed symptoms of the carcinoid syndrome-specifically, paroxysmal wheezing and flushing, without diarrhea. Signs or symptoms frequently associated with endobronchial tumors, such as cough, hemoptysis, localized wheeze, or recurrent infections, were uniformly absent.

Diagnosis. The mean time from the onset of symptoms to the discovery of a pulmonary lesion underlying the patients' Cushing's syndrome was 24 months. During this period, the patients underwent a wide variety of diagnostic tests to determine the cause of their hypercortisolism. In all patients, the diagnosis of Cushing's syndrome was suspected on clinical grounds and confirmed by elevated levels of urinary free cortisol and serum cortisol, which failed to decrease with a low-dose dexamethasone suppression test. The differential diagnosis for the cause of Cushing's syndrome was then narrowed in all patients to either pituitary hypersecretion of ACTH (Cushing's disease) or ACTH secretion from a nonpituitary (ectopic) source by documentation of elevated serum ACTH levels. Mean serum ACTH in these patients was 109 $\mathrm{pg} / \mathrm{ml}$ (normal 6 to $76 \mathrm{pg} / \mathrm{ml}$ ).

In five of the six patients who underwent a high-dose dexamethasone suppression test, the cortisol levels suppressed, initially suggesting the erroneous diagnosis of Cushing's disease. This misleading result was followed in each case by CT 


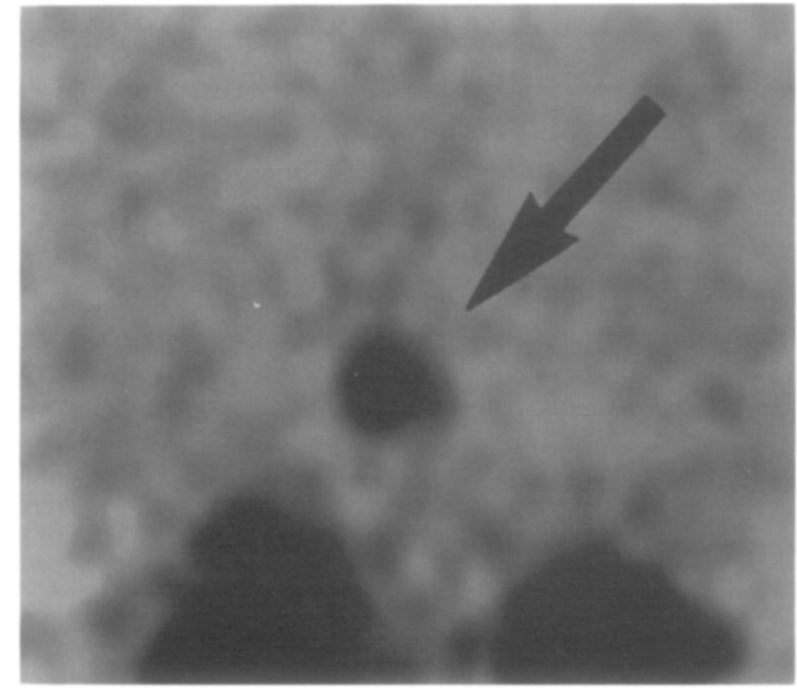

Fig. 1. Octreotide scan demonstrating activity in the subcarinal region (arrow) in a patient with recurrent Cushing's syndrome 29 months after right lower lobectomy (patient 4). At reexploration a subcarinal node containing metastatic carcinoid was discovered. The areas of uptake inferiorly represent the liver and spleen.

and/or magnetic resonance imaging (MRI) of the brain to examine the sella turcica for the presence of a pituitary tumor. In one of these patients (patient 3), brain MRI was believed to show some irregularity of the anterior pituitary, and transsphenoidal hypophysectomy was carried out directly. Pathologic examination revealed only pituitary hyperplasia, and the patient's condition did not improve. Ultimately, a chest CT scan was performed in this patient to demonstrate his bronchial carcinoid tumor, leading to appropriate treatment.

In the other four patients with misleading suppression after high-dose dexamethasone, brain studies did not demonstrate a pituitary lesion. This nondiagnostic result led to a search for an ectopic source of ACTH. Bilateral petrosal sinus catheterization for measurement of serum ACTH levels was performed in two of these patients and demonstrated a higher central than peripheral ACTH level in one (patient 2). On that basis, this patient underwent a transsphenoidal hypophysectomy, also without improvement. Adrenal tumors, although unlikely in the setting of elevated serum ACTH levels, were nevertheless ruled out in three of these four patients by abdominal CT. Ultimately, chest CT demonstrated a nodule and led to the correct diagnosis in each of these four patients.
The single patient in whom cortisol levels failed to suppress on high-dose dexamethasone testing (patient 6) also underwent brain MRI, which confirmed the absence of a pituitary lesion, and abdominal CT, which excluded adrenal masses. The results of petrosal sinus catheterization also supported the diagnosis of a nonpituitary ACTH source in this patient. A nodule was then identified on a chest CT, leading to appropriate treatment by nodule excision.

The final patient (patient 7) did not undergo a high-dose dexamethasone test but also underwent petrosal sinus catheterization, which suggested a nonpituitary ACTH source. Again, brain MRI revealed a normal sella turcica and abdominal CT revealed no adrenal masses. In this patient, both a chest roentgenogram and an initial chest $\mathrm{CT}$ scan revealed no lesions. An octreotide scan was performed because of the high suspicion of a carcinoid tumor given the experience with the other patients in this series, all of whom were seen before this patient. This study revealed an area of uptake in the left upper lobe. The presence of this lung nodule was then confirmed by chest CT repeated with finer cuts. The two other times an octreotide scan was performed were in the same patient when the hormone levels failed to normalize after initial resection, and in a patient in whom recurrent Cushing's syndrome developed 29 months after the initial resection (see below). In each of these patients, the scan localized recurrent disease that was surgically resected, in the ipsilateral subaortic region and in the subcarinal area (Fig. 1), respectively.

The initial chest roentgenogram showed no lesion in six of the seven patients. The lesions on chest CT and MRI were in the right middle lobe in three patients, the right lower lobe in two patients, and the left upper lobe in two patients. They ranged in size from $7 \mathrm{~mm}$ to $2.5 \mathrm{~cm}$ in maximal diameter with a mean of $1.5 \mathrm{~cm}$. Enlarged mediastinal lymph nodes were identified on chest CT in one patient. All of the patients underwent bronchoscopy, which identified no endobronchial lesions. Other than bronchoscopy, the only preoperative procedure performed in an attempt to establish a tissue diagnosis was a single attempted transthoracic needle biopsy, which recovered normal lung tissue.

Surgical procedures and outcome. All seven patients eventually underwent surgical resection of a bronchial carcinoid tumor. In all patients, ACTH levels fell to normal range within 1 week of the final intrathoracic operation. Four of the seven, however, required a second procedure for persistent or recur- 

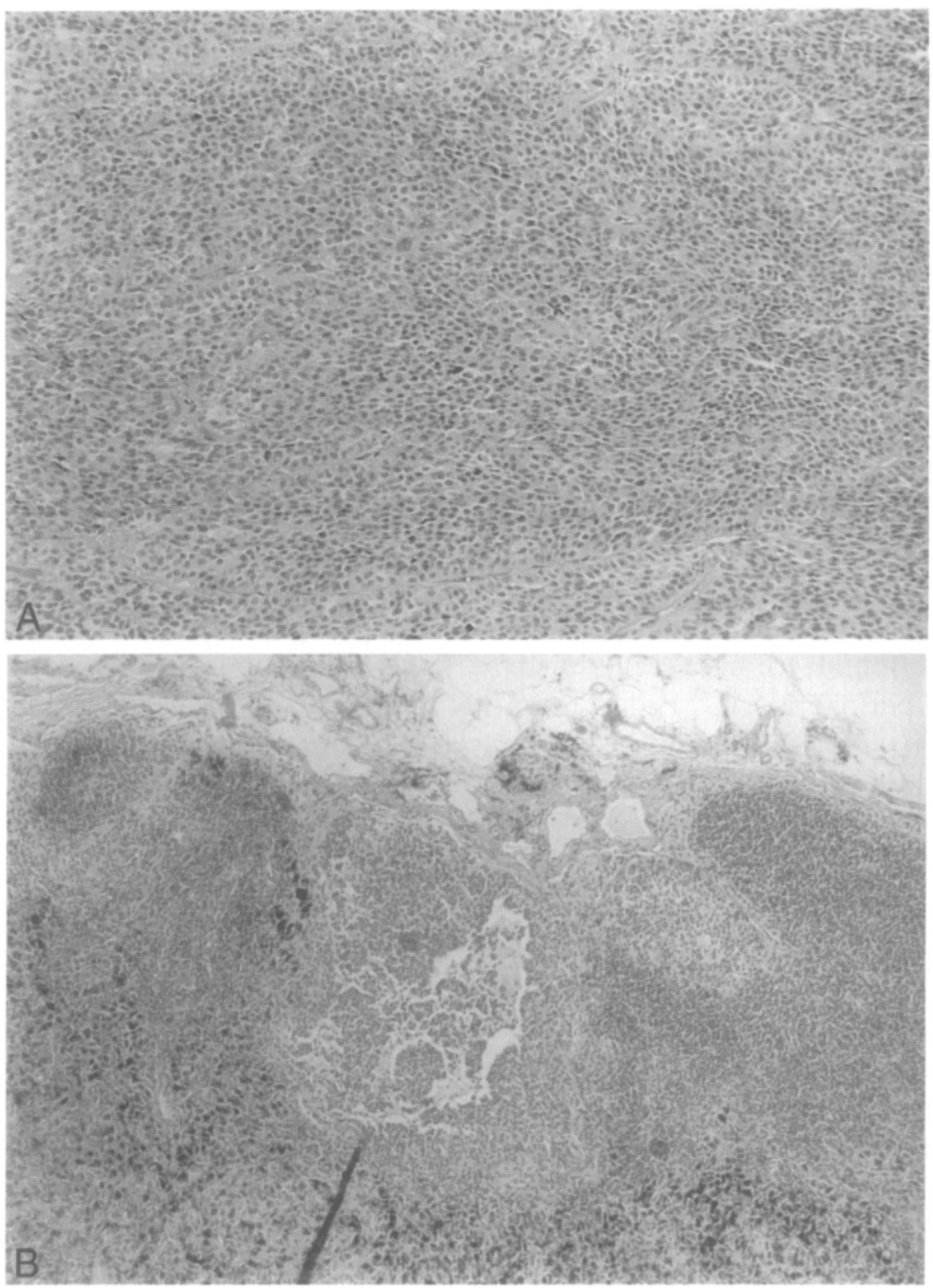

Fig. 2. A, Photomicrograph (hematoxylin and eosin stain, original magnification $\times 10$ ) of section of the primary tumor from patient 4 , demonstrating the classic features of a typical carcinoid. B, Photomicrograph (original magnification $\times 2.5$ ) of involved lymph node from the same patient. Areas of tumor invasion and surrounding normal lymph node are visible.

rent hypercortisolism before achieving a lasting cure. In one of these patients (patient 2), the second procedure was bilateral adrenalectomy. The six patients who were ultimately rendered free of symptoms and biochemically cured by intrathoracic procedures remain so a mean of 59 months after the operation (range 5 to 180 months). No perioperative complications developed.

The primary pulmonary resections performed included formal lobectomy in three patients, anatomic segmentectomy in one, wedge resection in two, and precision cautery excision in one. In all patients, the interlobar regions and mediastinum were palpated for enlarged lymph nodes, and these were resected when present (four patients). In one patient, this policy identified involved inferior pulmonary ligament nodes on frozen section examination and resulted in conversion of a wedge resection to a lobectomy.

In this small group of patients, no clear correlation existed between extent of initial resection and outcome. Three of the six patients who were ultimately cured by intrathoracic procedures required a second chest exploration for recurrent or persistent Cushing's syndrome. Two of these three patients had undergone an anatomic resection. The secondary procedures included mediastinal lymphadenectomy 29 months after lobectomy in one patient (Fig. 1) and completion lobectomy with mediastinal 
lymphadenectomy 12 days and 1 month after wedge resection and segmentectomy, respectively. Each of these patients remain free of symptoms 20,180 , and 9 months after the second procedure. In contrast to these patients, two of whom underwent anatomic resections only to have a relapse, the patient who underwent the least extensive initial resectionprecision cautery excision-required no further treatment and remains apparently free of disease 18 months after the initial procedure. The other two patients, who underwent primary lobectomy, are well 29 and 96 months after the operation.

Three patients underwent transsphenoidal hypophysectomy before pulmonary resection. One of these patients underwent two transsphenoidal procedures. Each of these patients, including the one (patient 2) who was found to have a gradient between central and peripheral ACTH levels on petrosal sinus catheterization, was found histologically to have pituitary hyperplasia without adenoma. The findings of hyperplasia and high central ACTH secretion were explained on examination of the carcinoid tumor that was ultimately resected from the right middle lobe of patient 2. Immunostaining revealed this lesion to secrete both ACTH and corticotropin-releasing hormone. This phenomenon has been previously described in the literature. ${ }^{6}$ This patient ultimately required bilateral adrenalectomy for recurrent Cushing's syndrome with no clear source 14 months after pulmonary resection, and the other two who underwent transsphenoidal hypophysectomy were cured by pulmonary resection.

Pathology and outcome. Five of the seven resected tumors were considered to be typical carcinoids by the standard histologic criteria established by Arrigoni, Woolner, and Bernatz ${ }^{7}$ (Fig. 2). However, four tumors, including both atypical tumors, demonstrated either extensive lymphatic or extensive vascular invasion. In the five cases in which lymph nodes were present in the surgical specimen, they were positive for metastatic carcinoid in four. The three tumors that were immunostained were positive for ACTH.

In contrast to the lack of a relationship between extent of resection and outcome, there did appear to be a correlation between the intrinsic aggressiveness of the tumors and outcome in these patients. All four patients with extensive lymphatic or vascular invasion required a second procedure to be cured of Cushing's syndrome. Two of these patients had involved lymph nodes at the time of initial operation. All three patients who had both typical carci- noid and no evidence of aggressive local invasive characteristics were cured by the initial resection.

The failure of the initial resection to cure four patients appears in at least three to have been due to unresected metastatic disease in lymph nodes. In the patient (patient 4) who underwent mediastinal lymphadenectomy after lobectomy, a single subcarinal node was found to contain metastatic carcinoid tumor (Fig. 2). In the patient (patient 7) who underwent completion lobectomy and mediastinal lymphadenectomy after segmentectomy, two of five lymph nodes were found to contain metastatic carcinoid, including a subaortic lymph node. Finally, in the patient (patient 1) who underwent completion lobectomy and mediastinal lymphadenectomy after wedge resection, three of five hilar lymph nodes and one lobar node were found to contain metastatic carcinoid. In total, at least three of seven patients $(43 \%)$ had N2 disease and four of seven (57\%) had diseased lymph nodes at some level.

\section{Discussion}

Although it contains only seven cases, this series is among the largest reported of ACTH-secreting bronchopulmonary carcinoid tumors resulting in Cushing's syndrome. ${ }^{2,3}$ The preponderance of published information on this association is in the form of individual case reports. ${ }^{2}$ Taken together, this and previous series suggest that these tumors are markedly more aggressive than hormonally quiescent typical carcinoids. As a result, these tumors require more aggressive surgical control than other typical carcinoids. Further, our experience with this uncommon disease process allows us to suggest a diagnostic algorithm that could avert much of the significant patient suffering and diagnostic expense related to the lesion.

As in previous series, all of our patients had symptoms of glucocorticoid excess without signs or symptoms referable to the local effects of the pulmonary tumor. In $86 \%$ of our patients the chest roentgenogram showed no abnormalities, similar to the figure (67\% of patients) in each of the two prior series of carcinoids causing Cushing's syndrome. None of our patients had a tumor identified within the airways at bronchoscopy, similar to the figures ( $100 \%$ and $75 \%$ of patients with normal bronchoscopic results) in the two prior series. These results are in stark contrast to patients with hormonally inactive bronchial carcinoids, more than half of whom have cough, hemoptysis, or dyspnea; more than $75 \%$ of whom have an abnormalities on the 


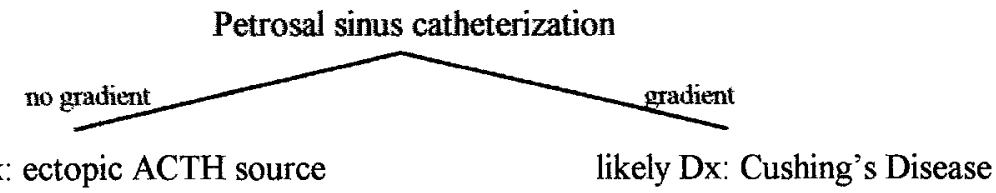

likely Dx: ectopic ACTH source<smiles>CCC</smiles>

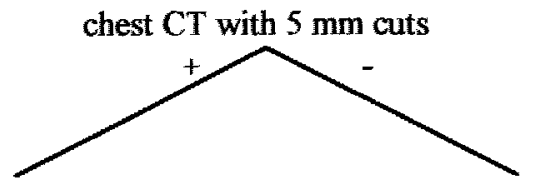

anatomic pulmonary resection with mediastinal lymph node dissection

\begin{abstract}
octreotide scan
\end{abstract}

\section{likely Dx: Cushing's Disease}<smiles>C1CCCC1</smiles>

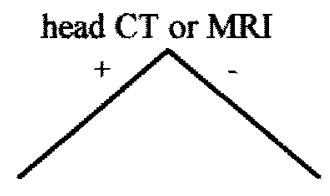

transsphenoidal
hypophysectomy

chest CT with $5 \mathrm{~mm}$ cuts +/- abdominal CT

Fig. 3. Recommended diagnostic algorithm for patients with Cushing's syndrome and elevated serum ACTH. $D x$, Diagnosis; $A C T H$, adrenocorticotropin; $C T$, computed tomography; $M R I$, magnetic resonance imaging.

chest roentgenogram; and in whom tumors are frequently visible on bronchoscopic examination. ${ }^{1,8,9}$ The ACTH-secreting carcinoids, then, would appear to fall within the subcategory of carcinoids identified by Wilkins and associates ${ }^{10}$ as "peripheral pulmonary carcinoids."

With pulmonary tumors as small as those in this series, chest $\mathrm{CT}$ is the most reliable diagnostic modality. When $5 \mathrm{~mm}$ cuts were used, this test identified the tumor in each of our patients. The ideal work-up of these patients, then, would include early, high-resolution chest CT. As in previous series, however, there was a significant delay in reaching an accurate diagnosis in our patients. The average time to diagnosis was 24 months. A large factor in this delay is unavoidable-the normal chest roentgenographic findings and absence of pulmonary symptoms. Another factor, however, was the fact that most of these tumors (83\%) misleadingly were suppressed on high-dose dexamethasone suppression testing. This was documented in one of the prior series, ${ }^{3}$ but not with the frequency seen in this series. It has been noted by others that metyrapone stimulation $^{11}$ and ovine corticotropin-releasing hormone stimulation ${ }^{12}$ are similarly nonspecific in identifying the source of ACTH as ectopic when that source is a carcinoid. The classic tests used to differentiate central from ectopic hypercortisolism, then, appear to be relatively unhelpful in this group of patients. This inevitably leads to the performance of other studies, such as brain and abdominal CT or
MRI and inferior petrosal sinus catheterization, ${ }^{13}$ when a chest CT might otherwise be performed first.

Given the unreliability of high-dose dexamethasone suppression and other biochemical tests, and the fact that the thorax is the most common site of ectopic ACTH secretion if one includes small-cell carcinoma of the lung, ${ }^{14}$ we propose a more efficient approach to diagnosis in patients with Cushing's syndrome and elevated ACTH (Fig. 3). This approach would begin with inferior petrosal sinus catheterization and proceed directly to chest CT when catheterization suggests an ectopic source. Such an approach would be likely to decrease both the time to diagnosis and the cost of coming to a diagnosis, because brain CT or MRI and abdominal CT would be rendered unnecessary, and the confusion surrounding the suppression and stimulation testing results would be averted. As demonstrated by our patient with an ectopic source of both ACTH and corticotropin-releasing hormone, petrosal sinus catheterization can occasionally be misleading, but this would appear to be an exceedingly rare event. Although submitting the vast majority of patients who have a central source for their Cushing's syndrome to petrosal sinus catheterization may strike some as unduly invasive, adoption of such a schema is the only way to assuredly prevent the minority with an ectopic source from undergoing unnecessary transsphenoidal hypophysectomy. Finally, octreotide scanning (see Fig. 1) may be useful in the event that all evidence points to an ectopic source but chest CT 
is unrevealing. ${ }^{15}$ In each instance in which we used this imaging modality in patients with recurrent or residual disease, it correctly directed us to the site of disease.

This series of cases emphasizes that many of these tumors are relatively aggressive and therefore require complete mediastinal lymph node dissection for cure. Three of our seven patients (43\%) had involved, resectable mediastinal lymph nodes, similar to the finding of $35 \%$ to $54 \%$ abnormal lymph nodes in prior studies. ${ }^{2,5}$ Although the majority of carcinoids in this and previous series of carcinoidassociated Cushing's syndrome are "typical" carcinoids, this rate of lymphatic metastasis is remarkably higher than the $4 \%$ to $11 \%$ rate seen for all typical carcinoids. ${ }^{8,10,16}$ These metastatic rates are higher, in fact, than that reported in a recent, representative series of atypical carcinoids in which only $22 \%$ of patients had $\mathrm{N} 2$ disease at the time of surgical treatment. ${ }^{17}$ In a previously published series of 111 patients from our institution, consisting of typical and atypical bronchopulmonary carcinoids, although five of the 11 patients with atypical tumors died of metastatic disease an average of 33 months after the operation, the only patient who required a second thoracotomy for locally recurrent disease was the single patient with an ACTH-secreting tumor (included in the current series). In that series, lymph node metastases were found with $5 \%$ of typical and $36 \%$ of atypical tumors, and no patient died of spread of a typical carcinoid. ${ }^{10}$

This information, coupled with our finding that $57 \%$ of the tumor specimens demonstrate either lymphatic or vascular invasion, suggests that carcinoids which secrete ACTH, although they may not meet standard criteria for "atypicality" and appear to have a lower mortality rate than nonsecreting, atypical carcinoids, nevertheless demonstrate more malignant characteristics than nonsecreting, typical carcinoids. These tumors appear to lie somewhere on the spectrum of malignancy between hormonally quiescent typical and atypical carcinoids. It would seem appropriate to label them Kulchitsky cell carcinoma type IIb by the classification scheme of Paladugu and associates, ${ }^{18}$ bearing metastatic potential similar to atypical carcinoids or well-differentiated neuroendocrine carcinomas according to the classification system proposed by Warren, Faber, and Gould, ${ }^{19}$ but without the same ramifications for survival.

Clearly, adequate surgical treatment for tumors that demonstrate such high rates of mediastinal lymph node metastasis must include mediastinal lymph node dissection. Control of these tumors will be accomplished with the most regularity by adhering to an approach of anatomic resection with routine, complete mediastinal lymph node dissection. The use of video-assisted techniques in these patients would be inappropriate.

In summary, bronchopulmonary carcinoid tumors that secrete ACTH are a distinct clinical and pathologic entity. These tumors are generally peripheral in location and cause symptoms resulting from hypercortisolism rather than from local tumor effects. Their discovery may be difficult but can be made simpler by adhering to the diagnostic plan outlined herein. Although they are usually typical carcinoids by standard histologic criteria, they have a much greater metastatic potential than hormonally quiescent typical carcinoids and would appear to more closely resemble atypical carcinoids in this regard. Surgical treatment of these tumors, therefore, should be approached in the same manner as has been proposed for more aggressive malignant tumors and should include anatomic resection and routine, thorough mediastinal lymph node dissection. This approach will result in high rates of cure.

\section{REFERENCES}

1. Harpole DH Jr, Feldman JM, Buchanan S, Young WG, Wolfe WG. Bronchial carcinoid tumors: a retrospective analysis of 126 patients. Ann Thorac Surg 1992;54:50-5.

2. Pass HI, Doppman JL, Nieman L, Stovroff M, et al. Management of the ectopic ACTH syndrome due to thoracic carcinoids. Ann Thorac Surg 1990;50:52-7.

3. Limper AH, Carpenter PC, Scheithauer B, Staats BA. The Cushing syndrome induced by bronchial carcinoid tumors. Ann Intern Med 1992:117:209-14.

4. Carpenter PC. Diagnostic evaluation of Cushing's syndrome. Endocrinol Metab Clin North Am 1988;17:445-72.

5. Zeiger MA, Pass HI, Doppman JD, et al. Surgical strategy in the management of non-small cell ectopic adrenocorticotropic hormone syndrome. Surgery 1992;112:994-1001.

6. Schteingart DE, Lloyd RV, Akel H, et al. Cushing's syndrome secondary to ectopic corticotropic releasing hormoneadrenocorticotropin secretion. J Clin Endocrinol Metab 1986;63:770-5.

7. Arrigoni MG, Woolner LB, Bernatz PE. Atypical carcinoid tumors of the lung. J Thorac Cardiovasc Surg 1972;64:413-21.

8. Okike N, Bernatz PE, Woolner LB. Carcinoid tumors of the lung. Ann Thorac Surg 1976;22:270-5.

9. Hurt R, Bates M. Carcinoid tumours of the bronchus: a 33 year experience. Thorax 1984;39:617-23.

10. Wilkins EW, Grillo HC, Manchuria AC, Scannell JG. Changing times in surgical management of bronchopulmonary carcinoid tumor. Ann Thorac Surg 1984;24:699-713.

11. Leinung $M C$, Young $W F$, Whitaker, MD, Scheithaner BW, Trastek VF, Kvols L. Diagnosis of corticotropin producing 
bronchial carcinoid tumors causing Cushing's syndrome. Mayo Clin Proc 1990;65:1314-21.

12. Lytras N, Grossman A, Perry L, et al. Corticotropin releasing factor: responses in normal subjects and patients with disorders of the hypothalamus and pituitary. Clin Endocrinol 1984;20:71-84.

13. Oldfield EH, Doppman JL, Nieman LK, et al. Petrosal sinus sampling with and without corticotropin-releasing hormone for the differential diagnosis of Cushing's syndrome. N Engl J Med 1991;325:897-905.14.

14. Shepherd FA, Laskey J, Evans WK, Goss PE, Johansen E, Khamsi F. Cushing's syndrome associated with ectopic corticotropin production and small-cell lung cancer. J Clin Oncol 1992;10:21-7.

15. Philipponneau M, Nocaudie M, Epelbaum J, et al. Soma- tostatin analogs for the localization and preoperative treatment of an adrenocorticotropin-secreting bronchial carcinoid tumor. J Clin Endocrinol Metab 1994;78:20-4.

16. McCaughan BC, Martini N, Bains MS. Bronchial carcinoids. J Thorac Cardiovasc Surg 1985;89:8-17.

17. Marty-Ane C-H, Costes V, Pujol, J-L, Lauzen M, Baldet P, Mary $\mathrm{H}$. Carcinoid tumors of the lung: Do atypical features require aggressive management? Ann Thorac Surg 1995;59: 78-83.

18. Paladugu RR, Benfield JR, Pak HY, Ross RK, Teplitz RL. Bronchopulmonary Kulchitsky cell carcinomas. Cancer 1985; 55:1303-11.

19. Warren WH, Faber LP, Gould VE. Neuroendocrine neoplasms of the lung. J Thorac Cardiovasc Surg 1989;98: $321-32$.

\section{Bound volumes available to subscribers}

Bound volumes of The Journal of Thoracic and Cardiovascular Surgery are available to subscribers (only) for the 1997 issues from the Publisher, at a cost of $\$ 110.50$ for domestic, $\$ 139.64$ for Canadian, and $\$ 130.50$ for international subscribers for Vol. 113 (January-June) and Vol. 114 (July-December). Shipping charges are included. Each bound volume contains a subject and author index and all advertising is removed. Copies are shipped within 60 days after publication of the last issue of the volume. The binding is durable buckram with the Journal name, volume number, and year stamped in gold on the spine. Payment must accompany all orders. Contact Mosby-Year Book, Inc., Subscription Services, 11830 Westline Industrial Drive, St. Louis, Missouri 63146-3318, USA; phone $800-453-4351$ or 314-453-4351.

Subscriptions must be in force to qualify. Bound volumes are not available in place of a regular Journal subscription. 